\title{
O subfinanciamento do Sistema Único de Saúde e seus rebatimentos no enfrentamento da Covid-19
}

| ${ }^{1}$ Diego de Oliveira Souza |

1 Universidade Federal de Alagoas. Arapiraca-AL, Brasil (diego.souza@arapiraca.ufal.br). ORCID: 0000-0002-1103-5474

Recebido em: 05/06/2020

Aprovado em: 23/06/2020

Revisado em: 26/06/2020

A coronavirus disease 2019 (Covid-19) assolou o mundo em 2020, tendo assumido um caráter universal cerca de dois meses após a descoberta do seu agente etiológico (o SARS-CoV-2, uma nova cepa de coronavírus), em 7 de janeiro de 2020, em Wuhan, China. Em 11 de março, a Organização Mundial da Saúde (OMS) declarou que a doença possuía caráter pandêmico, o que passou a mobilizar os diversos governos nacionais contra a propagação do vírus e para a assistência aos indivíduos infectados, na tentativa de evitar o crescimento de novos casos e óbitos.

As respostas governamentais passam, sobremodo, pela capacidade dos sistemas de saúde de cada país. Até mesmo as medidas de distanciamento social possuem, como horizonte prioritário, a diminuição da velocidade de propagação a fim possibilitar o tempo necessário para que tais sistemas se estruturem. O problema é que muitos desses sistemas possuem um histórico de "sabotagem" engendrado na dinâmica neoliberal internacional, decerto articulado aos interesses de grupos políticos e econômicos internos em cada país.

Pensando nessa questáo, propomos o texto em tela com o objetivo de contribuir com as reflexôes sobre os rebatimentos do desmonte do Sistema Único de Saúde (SUS) no enfrentamento da pandemia de Covid-19 (ou, no caso dos limites 
nacionais, epidemia). Convém esclarecer que uma das dimensôes mais eminentes desse desmonte reside no processo de subfinanciamento perene que marca sua institucionalização, a qual tomamos como mediação de análise. Sobre isso, Mendes (2013, p. 987) é taxativo ao afirmar que "a história do Sistema Único de Saúde (SUS) é marcada pelos problemas de financiamento. Os recursos públicos envolvidos sempre foram insuficientes para garantir uma saúde pública, universal, integral e de qualidade", implicando, por parte de seus defensores, uma longa batalha para a sobrevivência do sistema.

Trata-se de um cenário que vai de encontro ao direcionamento ideopolítico do movimento da Reforma Sanitária do qual se originou o SUS, porquanto se pressupunha um sistema universal, capaz de ser resolutivo ante as iniquidades de saúde de um país de dimensôes continentais e com profundas desigualdades. Obviamente, um sistema ancorado nessa doutrina demandaria um financiamento em outro patamar, tendo em vista que, historicamente, o financiamento tem orbitado em torno de 3 a 4\% do produto interno bruto - PIB (SOUZA, 2019).

Em vez disso, o SUS tem trilhado seu caminho sob a tensão de interesses do grande capital, notadamente forjados nas diretrizes (im)postas pelo Banco Mundial desde a década de 1990, mas ecoados pelos seus porta-vozes nacionais. Mais recentemente, entre 2017 e 2019, o Banco Mundial voltou a intensificar seu argumento de contrarreforma do SUS, tergiversando sobre o subfinanciamento ao evocar a necessidade de gerir os recursos de forma mais eficiente. Ainda que a eficiência possa ser melhorada, o alcance do SUS tem sido limitado por um financiamento aquém do pretendido e necessário (a exemplo da reivindicação do movimento da Reforma Sanitária, que exigia $10 \%$ do PIB para a saúde pública). A pedra de toque dessa proposta é destituir a possibilidade de universalidade plena, ao se defender a ideia de "cobertura universal", com um pacote mínimo de serviços que não, necessariamente, enfrenta as iniquidades de saúde ou garante atenção integral (SOUZA, 2020a).

Em termos comparativos, dados da Organization for Economic Cooperation and Development (OECD) mostram que o Brasil ocupa a 40a posição entre 49 países comparados quando se trata de financiamento público em saúde, com $4 \%$ do PIB em 2016. Os Estados Unidos (EUA), mesmo tendo um sistema voltado aos interesses dos seguros de saúde desde sua concepção, tiveram um financiamento público de 14,3\% do PIB em 2018. ${ }^{1}$ Países da América Latina, como Costa Rica (5,7\%), Colômbia $(5,3 \%)$ e Chile (5,2\%) estão à frente do Brasil na escala da OECD (2019). 
Quando se trata do financiamento público per capita, a situação é ainda pior, quando o Brasil cai para a 45ª posição (com 551,00 dólares por habitante, em 2016), sendo ultrapassado por países como Turquia (\$ 957,00) e México $(\$ 586,00)$. EUA, que encabeçam a lista, têm o financiamento público per capita 16,24 vezes maior que o brasileiro, com 8.949,00 dólares por habitante. Novamente, Chile $(\$ 1.272,00)$, Costa Rica $(\$ 965,00)$ e Colômbia $(\$ 706,00)$ ficaram à frente do Brasil. Na escala da OECD, o Brasil ficou à frente apenas de África do Sul (\$460,00), China (\$ 399,00), Indonésia (\$136,00) e Índia (\$ 52,00) (OECD, 2019).

A situação do SUS pregressa à epidemia já era bastante preocupante, ainda mais considerando a Emenda Constitucional (EC) 95 de 2016, quando se aprofundaram as medidas de austeridade econômica ao congelar os "gastos" públicos por vinte anos, a contar de 2018. Como já demonstraram Reeves et al. (2014), diversas naçóes tenderam a sacrificar o investimento em saúde diante de ajustes fiscais desse tipo e, no caso brasileiro, essa vem sendo a realidade objetiva.

Esclarecemos que, aqui, recorre-se ao termo rebatimento no sentido de implicaçóes que geram efeitos/reflexos que retornam à epidemia, no caso ora em análise, sob a forma de obstáculos ao enfrentamento dela com a eficiência pretendida. É o que temos constatado a partir do desmonte do SUS, considerando que o Brasil se tornou um dos epicentros da pandemia ao final de maio de 2020 (WHO, 2020). Entre outros motivos, a descaracterização do SUS no bojo de seu desmonte coloca limitaçôes para suas açôes de promoção da saúde e prevenção de doenças, o que poderia ser peremptório à mitigação da propagação do coronavírus.

Além disso, o prognóstico de cura dos casos mais graves está relacionado à disponibilidade de recursos de saúde, tais como leitos de unidade de terapia intensiva (UTI), respiradores mecânicos e quantitativo da força de trabalho em saúde (EMANUEL et al., 2020; REMUZZI; REMUZZI, 2020), questôes para as quais os investimentos em saúde estão imbricados. A título de exemplo, no início de maio, quatro estados (Pernambuco, Rio de Janeiro, Ceará e Roraima) e oito capitais (Manaus, Recife, Rio de Janeiro, Fortaleza, Boa Vista, Belém, São Luís e São Paulo) já tinham a ocupação dos leitos de UTI acima de 90\%.

Não por acaso, o Brasil se destaca na taxa de letalidade, sendo o vice-líder desse quesito na América do Sul, com 5,62\%, atrás apenas do Equador, com 8,51\%, até 4 de maio de 2020. O Peru, segundo país com mais casos no continente sulamericano, possui letalidade de $2,73 \%$, quase $50 \%$ menor que a brasileira. O Chile, 
país que vem na sequência com mais casos, possui letalidade de 1,12\%, ratificando a disparidade em termos de gravidade da doença mesmo entre os países sul-americanos - taxas calculadas a partir do Situation Report 136 (WHO, 2020).

Já vimos que o Chile possui investimento público em saúde superior ao brasileiro. Não é o caso do Peru, com investimento que só chega a 5\% quando somados os valores da esfera pública e da privada, sendo a primeira em torno de $3 \%$ do total (WORLD BANK, 2020). Todavia, o Peru vem se destacando no orçamento implementado no curso da pandemia, porquanto seja o país que mais investiu proporcionalmente ao PIB na América Latina (até 10 de maio de 2020), com 9\%, à frente do Brasil com $8 \%$ e, portanto, considerando o que os resultados sugerem, com maior eficiência (BARRÍA, 2020).

Convém esclarecer que o orçamento acima mencionado não se restringe ao aplicado em saúde, mas abrange também outras áreas, como o combate ao desemprego, o investimento em ciência e tecnologia e a liberação de orçamentos às empresas. Tal condição precisa ser entendida ante o caráter social multifacetado da saúde, para além de seus aspectos biológicos, o que ficou ainda mais evidente com a pandemia (SOUZA, 2020b), mas que há tempos comparece como premissa teóricoprática de movimentos sociais de saúde, a exemplo das reformas sanitárias italiana e brasileira. Nessa perspectiva, pressupóe-se o fortalecimento do setor saúde, mas com articulação consistente para além dele, alcançando outros complexos sociais importantes no processo saúde-doença. Esse é o horizonte do SUS, embora tenha sido diuturnamente contrariado no processo de desmonte em curso, o que também atinge outras políticas sociais relegadas pela dinâmica neoliberal.

Assim, os rebatimentos se revelam mútuos entre o subfinanciamento do SUS e o enfrentamento da pandemia: se o desmonte do SUS se coloca como obstáculo ao enfrentamento da pandemia; este, por sua vez, tende a trazer novas dificuldades ao SUS, não só durante o transcorrer do problema - com a saturação do sistema e o adoecimento e morte de trabalhadores da saúde - como também a médio e longo prazos. A título de exemplo, não será surpresa se os governos neoliberais equalizarem a questão fiscal com medidas ainda mais intensas de austeridade, a fim de compensar os orçamentos de emergência implementados no curso da pandemia, o que, certamente, agravará o processo de demonstre da saúde pública.

Ou se intensifica a "frente de batalha" contra o desmonte do SUS (e, por conseguinte, contra a dinâmica capitalista), ou a "asfixia" financeira da saúde 
pública produzirá cenários cada vez mais trágicos, não só em situaçôes emergenciais como a da Covid-19, mas cotidianamente, até mesmo porque agir apenas ante as emergências ("trocar o pneu com o carro andando") não é, de fato, a melhor maneira de impedir tragédias - ao contrário disso, tende a criar as condiçóes objetivas para situações cada vez mais trágicas.

\section{Referências}

BARRÍA, C. Coronavírus: os 10 países que mais gastaram para enfrentar a pandemia de covid-19. BBC News, 2020. Disponível em: https://www.bbc.com/portuguese/internacional-52721417. Acesso em: 30 maio 2020.

EMANUEL, E. J. et al. Fair Allocation of Scarce Medical Resources in the Time of Covid-19. The New England Journal of Medicine, v. 382, p. 2049-2055, 2020.

FOLHA DE SÃO PAULO. Quatro estados e oito capitais têm ocupação acima de $90 \%$ de leitos de UTI. 2020. Disponível em: https://wwwl.folha.uol.com.br/cotidiano/2020/05/quatro-estados-eoito-capitais-tem-ocupacao-acima-de-90-de-leitos-de-uti.shtml . Acesso em: 4 jun. 2020.

MENDES, A. A longa batalha pelo financiamento do SUSS. Saúde e Sociedade, v. 22, n. 4, p. 987-993, 2013. Disponível em <http://www.scielo.br/scielo.php?script=sci_arttext\&pid=S010412902013000400002\&lng=en\&nrm=iso>. Acesso em: 30 maio 2020. https://doi.org/10.1590/ S0104-12902013000400002.

ORGANIZAÇÃO MUNDIAL DASAÚDE. Folha informativa-Covid-19 (doença causada pelo novo coronavírus), 2020. Disponível em: https://www.paho.org/bra/index.php?option=com_co ntent\&view=article\&id=6101:covid19\&Itemid=875. Acesso em: 17 abr. 2020 .

ORGANIZATION FOR ECONOMIC COOPERATION AND DEVELOPMENT. Health at a Glance 2019: OECD Indicators. OCDEiLibrary, 2019. Disponível em: https://www.oecdilibrary.org/sites/4dd50c09-en/1/3/9/3/index.html?itemId=/content/publication/4dd50c09en\&mimeType=text/html\&_csp_=82587932df7c06a6a3f9dab95304095d\&itemIGO=oecd\& itemContentType=book. Acesso em: 21 maio 2020.

REEVES, A. et al. The political economy of austerity and healthcare: cross-national analysis of expenditure changes in 27 European nations 1995-2011. Health Policy, v. 115, n. 1, p. 1-8, 2014. REMUZZI, A.; REMUZZI, G. COVID-19 and Italy: what next? The Lancet, v. 395, n. 10231, p. 1225-1228, 2020.

SOUZA, D. O. A pandemia de COVID-19 para além das Ciências da Saúde: reflexóes sobre sua determinação social. Ciência \& Saúde Coletiva, no prelo. Disponível em http://www. cienciaesaudecoletiva.com.br/artigos/a-pandemia-de-covid19-para-alem-das-ciencias-da-saudereflexoes-sobre-sua-determinacao-social/17562. Acesso em: 19 maio 2020. 
SOUZA, D. O. Financeirização, fundo público e os limites à universalidade da saúde. Saúde em debate, v. 43, esp. 5, p. 71-81, 2019.

SOUZA, D. O. Under the leadership of the World Bank: challenges in, and perspectives of, the SUS counter-reform. Physis, v. 30, n. 1, e300101, 2020a. Disponível em: <http://www.scielo. br/scielo.php?script=sci_arttext\&pid=S0103-73312020000100300\&lng=en\&nrm=iso $>$. Acesso em: 4 jun. 2020. https://doi.org/10.1590/s0103-73312020300101.

WORLD BANK GROUP. Data World Bank, 2020. Disponível em: https://data.worldbank. org/indicator/SH.XPD.CHEX.GD.ZS. Acesso em: 5 jun. 2020.

WORLD HEALTH ORGANIZATION. Coronavirus disease 2019 (Covid-19). Situation Report 136, 2020. Disponível em: https://www.who.int/docs/default-source/coronaviruse/situationreports/20200511-covid-19-sitrep-112.pdf?sfvrsn=813f2669_2. Acesso em: 5 jun. 2020.

\section{Nota}

${ }^{1}$ É preciso fazer a ressalva de que os dados que estamos utilizando dizem respeito às despesas com saúde e que, na metodologia da OECD, contabilizam-se as despesas compulsórias junto às despesas governamentais. Com isso, a despesa pública nos EUA, devido à complexidade do sistema de saúde desse país e à sua repartição em vários subsistemas, tem os seguros obrigatórios contabilizados no referido dado. 